\title{
Um canto de santomensidade em Histórias da Gravana, de Olinda Beja
}

\section{A santomensidade chant in Histórias da Gravana, BY Olinda BEJA}

\author{
Thaíse de Santana Santos ${ }^{1}$ \\ Inara de Oliveira Rodrigues ${ }^{2}$
}

DOI: 10.11606/issn.1981-7169.crioula.2017.137486

RESUMO: Apresenta-se uma análise dos contos "Lembranças de Ponta Figo" e "Homenagem", da escritora são-tomense Olinda Beja, publicados em Histórias da Gravana (2011). O objetivo do trabalho é reconhecer como são representados os sentidos de identidade e resistência nessas narrativas. $O$ conjunto de contos que compõem a referida obra literária exala sentidos de santomensidade e, dessa maneira, a literatura apresenta-se como forma de resistência identitária com grande importância na construção de um ideário de nação.

ABSTRACT: An analysis of the short stories "Lembranças de Ponta Figo" and "Homenagem", published in Histórias da Gravana (2011), by Santomean writer Olinda Beja, is presented in this paper. This work aims to identify how identity and resistance are represented in these narratives. The collection of short stories in the referred literary work emanates a feeling of santomensity, so this literature is presented as a form of an identity resistance with a large emphasis on the construction of a nation ideal.

1 Mestranda em Estudos Literários na Universidade Federal de Viçosa. Pesquisadora no Grupo Literatura, História e Cultura: encruzilhadas epistemológicas (CNPq/UESC). 2 Professora Doutora do Curso de Letras (graduação e mestrado) da Universidade Estadual de Santa Cruz. Coordenadora do Grupo de Pesquisa Literatura, História e Cultura: encruzilhadas epistemológicas 
PALAVRAS-CHAVE: Identidade; Resistência; Literatura são-tomense contemporânea.

KEYWORDS: Identity; Resistance; Contemporaneous santomean literature.

"Agora sinto vontade de me apoderar do teu canhão, desmontá-lo peça a peça, refazê-lo e disparar não contra o teu texto, não na intenção de o liquidar, mas para exterminar dele a parte que me agride".

(Manuel Rui)

objetivo central deste artigo consiste em reconhecer e apontar algumas das especificidades da realidade sociocultural são-tomense a partir da análise dos sentidos de identidade e resistência presentes nos contos "Lembranças de Ponta Figo" e "Homenagem", publicados em Histórias da Gravana (2011), de Olinda Beja, considerando-se as experiências de migração vividas pelos narradores e personagens dessas narrativas. O livro ganhou notoriedade após ser selecionado para concorrer ao prêmio Portugal Telecom 2012, mas, de modo geral, a literatura de São Tomé e Príncipe, dentre as outras literaturas africanas escritas em português, é relativamente ainda pouco conhecida no Brasil, por variados motivos, dentre os quais se destacam problemas editoriais de distribuição e circulação.

Sobre as dificuldades de acesso a obras literárias são-tomenses, importa sublinhar a observação feita por Inocência Mata (2009) sobre a centralidade editorial exer- 
cida por Portugal e o privilégio dos escritores luso-descendentes no que diz respeito à publicação. Ela afirma também que não se deve obliterar a existência de um significativo sistema literário, pois a literatura são-tomense é, sim, uma literatura consolidada ${ }^{3}$.

Adotando-se uma perspectiva crítica em relação à citada dominância etnocultural, entende-se, como pressuposto deste estudo, que o colonialismo "dividiu o mundo em duas partes, hierarquicamente constituídas, e o centro se consolidava apenas através da existência do outro colonizado" (BONNICl, 2009, p. 264). No discurso hegemônico, a metrópole representa o centro, o lugar da civilização, da ciência e progresso, enquanto a colônia é lugar de atraso cultural, da ignorância e selvageria. Nesse sentido, a literatura produzida pela metrópole, durante o período colonial, cumpria o papel de afirmar a "superioridade" europeia e dirimir a cultura dos povos colonizados. Bonnici levanta alguns questionamentos acerca da situação das literaturas produzidas nas ex-colônias e nota que, se a relação entre metrópole e colônia sempre foi tensa, as literaturas escritas a partir da invasão colonial até o presente mostram as tensões inerentes aos processos colonialistas.

Essas literaturas, desse modo, dão voz aos povos que foram silenciados pelo regime colonial e constroem identidades que fogem a padrões estereotipados. Nessa acepção, "o pós-colonial pressupõe uma nova visão da sociedade que reflete sobre a sua própria condição periférica, intentando adaptar-se à lógica de abertura de novos espaços" (MATA, 2000 , p. 01). Entende-se que "toda identidade humana [seja ela individual ou coletiva] é construída e histórica. [...] Histó-

3 Inocência Mata em entrevista à Revista Crioula (2009, p. 6). 
rias inventadas, biologias inventadas e afinidades culturais inventadas vêm junto a toda identidade" (APPIAH, 1997, p. 242). Dessa maneira, a identidade não é inerente ao indivíduo, mas é construída historicamente, do mesmo modo que "as culturas nacionais são compostas não apenas de instituições culturais, mas também de símbolos e representações" (HALL, 2004, p. 50).

São Tomé e Príncipe, que conquistou sua independência em 1975, ainda vive intensamente o processo de construção de uma santomensidade, na qual se devem considerar embates entre os elementos da tradição em meio à realidade da globalização "como fábula"4. Isso significa reconhecer que a identidade é um processo atravessado por várias questões, com dimensões políticas, culturais e socioeconômicas. Nesse âmbito, a literatura continua sendo uma expressão artística fundamental na construção de reconhecimentos identitários.

Um canto de santomensidade configura-se em Histórias da Gravana ${ }^{5}$, livro de contos em que a escritora dá voz aos saberes ancestrais, tecendo suas narrativas a partir de soias ${ }^{6}$ e histórias contadas pelos mais velhos. Seu lugar de enunciação é Batepá, palco do maior massacre da história de São Tomé e Príncipe. A partir desse local, ela recorre a elementos da sociedade e da cultura de seu país para cantá-lo e assim proclamar uma identidade telúrica. São contadas histórias de vida desse povo, situadas em momentos anteriores e posteriores à independência de São Tomé e Príncipe, e entre a época das chuvas e a dos dias de sol ardente.

4 De acordo com Milton Santos (2000, p. 9): "Um mercado avassalador dito global é apresentado como capaz de homogeneizar o planeta quando, na verdade, as diferenças locais são aprofundadas".

5 Designa-se por gravana a estação seca do clima equatorial úmido de São Tomé e Príncipe. 6 Contos orais são-tomenses. 
As temáticas recorrentes nas narrativas concernem, principalmente, à condição periférica de determinados segmentos da sociedade são-tomense, a histórias de amores desencontrados, à exaltação dos mais velhos, à evocação ao mar, ao abandono e à exploração sexual das mulheres. Ademais, ao longo dos quinze contos, convive-se com os costumes, crenças, contempla-se a beleza dos lugares e das gentes, bem como também se pode conhecer um pouco da história do país. Ressalta-se que, antes de cada narrativa, provérbios escritos em língua forro, com tradução em português, servem de epígrafe aos contos. Além disso, o livro apresenta um glossário explicativo dos termos escritos nessa língua, o que se constitui, aliás, em estratégia comum dos escritores e escritoras dos países africanos de língua portuguesa, para mostrar que, se a língua oficial é o português, a expressão, nesse caso, é são-tomense.

Considerando-se o objetivo central da análise proposta, destaca-se, inicialmente, o conto "Lembranças de Ponta Figo", segunda narrativa da primeira parte do livro intitulada "Estação das chuvas". O conto estrutura-se como uma conversa, na qual o narrador-personagem, Mandioca, rememora sua infância na Roça de Ponta Figo, dirigindo-se a uma "dona" para contar as histórias do local, as quais giram em torno do velho Dedé. Este era um contratado de Cabo Verde, trabalhador das roças de cacau, homem muito sábio e solícito, querido pelas crianças do lugar. Exímio contador de histórias, transmitia por meio delas ensinamentos necessários à vida na comunidade: 
Havia aqui um homem, contratado de Angola, a quem chamavam o Carapinha que costumava ir para o rio pescar camarão. Só que não queria que ninguém o acompanhasse porque, dizia, depois sempre tinha que dividir o camarão com o outro. Aquilo era inveja mesmo que o homem tinha. Por mais que o avisassem que não devia ser assim, Carapinha continuava a ir sozinho para o rio e regressava com muswá cheio de camarão. Certa vez, porém, Carapinha não regressou. À noite todos se interrogavam pela sua ausência, mas àquela hora ninguém se aventurou em descer a grota até ao rio. Pela manhã três homens foram no seu encalço com os gritos da mulher e dos filhos nos ouvidos. Trouxeram Carapinha quase morto, sem roupa, sem muswá, sem camarão. Uma escorregadela numa pedra, um desequilíbrio e assim foi levado pela corrente que era forte devido a calema no mar. Ficou preso nos troncos dos bambus a gritar por socorro que ninguém ouviu. Mais umas horas e Carapinha teria morrido, força estava mesmo a largá-lo. A partir desse dia, Carapinha chamava sempre dois ou três amigos, com eles ia pescar camarão e com eles o dividia (grifos nossos). ${ }^{7}$

Mandioca mantém viva a memória do falecido Dedé e, ao recontar suas histórias, continua a ministrar seus ensinamentos, como também constrói uma narrativa de sua comunidade. Entende-se que a memória, "ao mesmo tempo em que nos modela, é também por nós modelada. [Memória e identidade] se conjugam, se nutrem mutuamente, se apoiam uma na ou-

7 BEJA, Olinda. Histórias da Gravana. São Paulo: Escrituras, 2011, p. 36. Todas as demais citações foram retiradas dessa edição, passando-se a indicar apenas as respectivas páginas. 
tra para produzir uma trajetória de vida, uma história, um mito, uma narrativa." (CANDAU, 2011, p. 16).

Em algumas culturas africanas, o velho é o representante do "saber da comunidade, o contador, o griot, inscrito numa tradição em que o 'ser idoso' e o ter conhecimento aprofundado das histórias dos antepassados são elementos que valorizam o indivíduo no grupo a que pertence" (FONSECA, 2003, p. 70). Nessa história de Dedé, recontada por Mandioca, fica clara a repreensão à avareza; mais especificamente, no trecho destacado, percebe-se o combate ao individualismo. São histórias que disciplinam e que educam. Não se pode deixar de observar também a aparição de vocábulos da língua forro, como o muswá, por exemplo, utilizado para denominar a armadilha usada na pesca ao camarão, segundo o glossário explicativo do livro. No trecho seguinte, Mandioca também relata à sua interlocutora seus gostos e peripécias da infância:

Eu gostava também dos outros miúdos da roça e era com eles que eu trepava às fruteiras, aos coqueiros, chupava cacau às escondidas dos mais velhos, roubava sape-sape e safú ainda verde, apanhava suim-suim... gostava muito de Sam Vilina que tratava dos meus bixôs quando se metiam nas unhas dos pés, que cantava para afastar os espíritos maus do meu corpo, que pisava angu só para mim, mas gostava mesmo era de Dedé, o velho Dedé sempre sorridente a mostrar os poucos dentes que ainda Ihe sobreviviam na boca, sempre disposto a contar soias, aventuras de um tempo que o trouxe para São Tomé e por aqui o deixou ficar (p. 34). 
Por intermédio das memórias do narrador-personagem, o leitor situa-se no ambiente físico e cultural do povo são-tomense. As palavras destacadas assinalam a língua forro: fruteiras diz respeito a um tipo de árvore de grande porte que dá a fruta-pão; o termo suim-suim refere-se a uma espécie de ave; o angu, ao contrário do que se conhece no Brasil, diz respeito a um purê de banana. Já o safú faz referência ao fruto do safuzeiro, e conta a tradição que quem comer desse fruto não mais sairá da ilha de São Tomé. Merecem ainda destaque as referidas soias, "contos orais santomenses que, para além da divulgação através da oralidade vêm encontrando, de maneira cada vez mais frequente, outras modalidades de registro" (QUEIROZ, 2009, p. 2).

Pode-se reconhecer, assim, o quanto, muito mais do que apenas inserir vocábulos originários de uma língua local, essa estratégia dá distintos contornos à língua portuguesa nas narrativas, diferenciando-se, dessa forma, do português falado/escrito nos outros países. O português é a língua predominante nas narrativas em questão, mas se mistura aos vocábulos e às expressões da língua forro, uma vez que, em muitas situações, não pode expressar a vivência são-tomense que elas representam. Por essa última perspectiva, não é difícil reconhecer que tais registros se imprimem como marcas de resistência cultural. Isso não significa, entretanto, uma idealização nostálgica do passado, mas o reconhecimento dos conflitos e perdas no presente.

A seguir, num relato aparentemente despretensioso, Mandioca denuncia um comportamento comum aos homens brancos do lugar e a precária condição em que vive: 
Quando aos sábados meu pai chegava a Ponta Figo e não me encontrava, já sabia que eu estava com Dedé e certamente a comer cachupa. Cachupa pobre, dona, que naquele tempo, carne era pouca. Nas noites de fundão era um espetáculo ver Dedé dançar, um gingar que não era só gingar de preto, aquilo era gingar de todas as raças do mundo (p. 36).

Mandioca não vivia com o seu pai, que era um morador, homem importante na comunidade local a partir da autoridade conferida pelo colonizador. Seu pai morava na cidade e, por esse motivo, ele só o via aos sábados. Em contrapartida, encontrava no velho Dedé o amor e a atenção cotidiana que Ihe faltavam, e por isso gostava tanto dele. A narrativa mostra que era comum as mulheres contratadas terem filhos desses homens importantes, frutos de relacionamentos que, muitas vezes enganosos, tinham fim quando elas engravidavam. Os filhos, geralmente, recebiam a atenção dos pais, mas não herdavam o seu nome, como foi o caso de Mandioca.

A referência à cachupa, uma espécie de feijoada preparada à base de feijão e milho, faz-se presente em quase todas as histórias. Diz respeito a um prato tradicional de Cabo Verde, país que sempre manteve relações estreitas com o "vizinho" São Tomé e Príncipe. Além de cozinhar, Dedé também dançava e encantava as mulheres com o seu gingado. Ele não tinha uma esposa, já vivera com muitas mulheres; no entanto, com nenhuma teve filhos, o que fez com que elas o abandonassem. Nas noites de dança, porém, "a conquista estava assegurada e a solidão dormia do lado de fora da cubata" (p. 36). Dedé era também um butadô vungu, aquele que canta 
e comanda o socopé, dança típica do lugar. Sentia-se mesmo pertencente àqueles costumes, àquela terra, como o menino Mandioca. Mais adiante, acontece a partida da "dona" e o lamento de Mandioca:

Por favor, dona, fica mais um pouco! Na nossa terra há tanta coisa para contar. Eu ficava aqui vários dias só a falar de Dedé. Nunca mais conheci ninguém como ele. Homem que tinha muita sabedoria e resposta sempre pronta para tudo. Na cidade dizem que também havia um chamado Sum Mé Novo Blanco que sabia tudo, mas em Ponta Figo era só Dedé! Dona está mesmo farta de me ouvir, eu vejo pelo seus pés... Mas dona me pediu para Ihe contar histórias de Ponta Figo... Então seus pés que tenham paciência... Dona gosta mesmo desta terra! Pois é, quem nasce como dona a ver este cais e este mar sem fim... nunca mais esquece (p. 37).

O personagem/narrador fecha seu baú de memórias lamentando a partida da "dona". Tem-se a impressão de que se trata da própria escritora, em seu trabalho de coleta de histórias de seu povo para criar as suas Histórias da Gravana, ao mesmo tempo em que essa "dona" parece também se referir ao interlocutor/leitor do texto, numa estratégia de aproximação para a partilha das memórias do narrador/personagem. Assim, o conto passa a constituir "espaços revividos da memória que, marcados pela oralidade, se traduzem em histórias de sentir para que se possa seguir contando e reinventando a potencialidade da criação poética na recriação e reinvenção da vida" (RODRIGUES, 2011, p. 30). 
No conto "Homenagem", a narradora faz um tributo a todas as mulheres africanas, das diferentes localidades, que saíram de suas terras para trabalhar nas roças de cacau e café em São Tomé e Príncipe. A narrativa gira em torno de Uaka, avó da narradora onisciente, já falecida, que tem sua história recuperada pela neta. A seguir, tem-se uma denúncia à exploração que aprisionou corpos e mentes:

De Uaka te passaram a nomear Custódia como se isso constasse das regras de um jogo sórdido e obscuro. E num relâmpago perdeste a identidade. Deixaste de ser tu, a guerreira ousada que em tua longínqua morada prometeste nova luz aos que ficaram em terra firme. Foi tua primeira derrota, a aniquilação do teu chamamento, da tua graça. $E$ isso jamais perdoaste que eu sei (p. 55).

Pode-se destacar da citação a ideia de que, com a perda do nome, Uaka perde também sua identidade. De acordo com Candau (2011, p. 68), "a nomeação, a memória e a identidade estabelecem relações muito fortes. Todo dever de memória passa em primeiro lugar pela restituição de nomes próprios. Apagar o nome de uma pessoa de sua memória é negar sua existência". A Uaka foi negado o chamamento do seu nome, uma perda simbólica que significou sua primeira derrota. A segunda foi o desfalecimento do seu corpo:

Gulosos foram depois os olhos dos homens que conheceram teu corpo, o desfloraram, o sulcaram e o 
encheram de saliências e reentrâncias como o sul da ilha, até o desfigurarem no rebentamento de tantas águas futuras e passadas (p. 56).

Nesse trecho, enfatiza-se a condição de subalternidade da mulher contratada na sociedade colonial. Ainda menina, ela foi explorada sexualmente pelo colonizador, pelo feitor ou qualquer um que estivesse numa posição superior ao do contratado. Nessa sociedade despótica e patriarcal, o homem, tanto mais aquele considerado importante, tinha direito aos corpos das mulheres - o que vale dizer que elas foram duplamente escravizadas e só se libertavam dessa condição com a morte, como é o caso de Uaka:

Mas por fim a tua alma se libertou de jugos e de ambições retomando a forma alada de uma qualquer ave do sul. Por isso resististe minha velha avó e só por isso serás sempre a luz da minha estrada onde os arcos de bambus se entrelaçam tentando cerrar-me por completo a luz do dia esquecendo-se que a tua força indomável a fará de novo ressurgir. [...] Envolta em mistérios de noites longas de carências e mágoas, poucas foram as tuas alegrias, mas soubeste legar-nos uma pujança indestrutível, muita fé, muita coragem (p. 56-57).

Percebe-se, no discurso da narradora, que a morte representa uma mudança de estado, uma fase de transição para outra existência. Nesse caso, a mulher volta a ser ave, existência que já experimentou, como aponta sua declaração: "retomando a forma alada de qualquer ave do sul". A figu- 
ra da ave faz-se presente também em outras narrativas, de modo geral, como metáfora da liberdade. Ainda que debilitada, Uaka, em vida, "esgravatava na terra ossame e mandioca para que ninguém morresse de fome" (p. 57). Solidarizava-se com seus companheiros refugiados, não os entregando aos seus senhores, ainda que isso lhe custasse mais chicotadas, mais dores ao seu corpo sofrido. Ela também sonhava com o regresso, pois acreditava que já estava há muito tempo fora do Gabão Grande.

Entende-se, de acordo com Hall (2013), que, numa situação de migração ou diáspora, os elos com a antiga terra permanecem, mas criam-se também outras fontes de identificação. Dessa forma, constrói-se uma identidade cultural híbrida. Percebe-se na narrativa que, longe de querer desvelar uma identidade primeira, a personagem Uaka deseja, com o retorno:

levar para o Gabão Grande todos os filhos do teu labor, botões de acácia rubra do sangue deixado nas plantações desse cacau que hoje o mundo inteiro consome e saboreia em barras retangulares de cores variadas sem noção alguma do seu verdadeiro gosto. Amargo, muito amargo. Seja ele Criollo, Forastero, Trinitário... Nas ilhas do equador foi o mais amargo de todos os cacaus produzidos por terras húmidas e quentes, muito quentes, muito húmidas. Um cacau com sabor à tua força hercúlea que te fez olhar sempre em frente e não temer a escuridão da vida (p. 56). 
Entretanto esse desejo não se realiza e, com a morte, enfim e tristemente, Uaka liberta-se do jugo colonial a que fora submetida desde sua juventude e se torna um símbolo de coragem e resistência para sua neta. Mais adiante, tem-se um apelo da narradora em prol das mulheres contratadas, das diferentes localidades africanas, que migraram para São Tomé e Príncipe:

Demos as mãos mulheres de todas as cores, muIheres das ilhas do meio do mundo, das ilhas onde o cacau ainda é amargo e sejamos, nem que seja apenas uma vez na vida, unidas e firmes no gesto de homenagens que elas merecem, elas, todas as corajosas mulheres que vieram antes de nós abrir os sulcos da escuridão onde plantaram o cacau e o café que ainda hoje, todos nós, saboreamos (p. 58).

Ao fim do conto, a narradora convoca as mulheres para, juntas, homenagearem todas as contratadas cabo-verdianas, moçambicanas, entre outras, que aportaram nas ilhas de São Tomé e Príncipe para trabalhar nas roças de café e cacau. MuIheres que foram oprimidas pelo sistema colonial e que provaram, juntamente com os homens, o gosto amargo da escravidão.

Conclui-se que o conjunto de contos que compõe Histórias da Gravana dissemina a cultura de um povo que se expressa por meio da variedade de línguas, dos costumes, das crenças, entre tantos outros relevantes aspectos. O resgate de histórias contadas pelos mais velhos alude ao pensamento de Walter Benjamin, segundo o qual "a experiência que 
passa de pessoa a pessoa é a fonte a que recorreram todos os narradores. E, entre as narrativas escritas, as melhores são as que menos se distiguem das histórias orais contadas pelos inúmeros narradores anônimos" (BENJAMIN, 1994, p. 198). Essas narrativas, além de cumprirem sua função estética, denunciam os desmandos do sistema colonial e permitem o protagonismo daqueles que foram oprimidos e colocados à margem nesse sistema. Podem-se reconhecer, também, por diferentes enfoques temáticos, certos símbolos e imaginários que produzem sentidos de identificação coletiva.

A literatura de São Tomé e Príncipe, assim, cumpre o papel de apresentar-se como forma de resistência identitária, com grande importância na construção do ideário da nação são-tomense. Em Histórias da Gravana, Olinda Beja deixa seu legado de santomensidade. 


\section{REFERÊNCIAS BIBLIOGRÁFICAS}

APPIAH, Kwame Anthony. Na casa de meu pai: a África na filosofia da cultura. Rio de Janeiro: Contraponto, 1997.

BEJA, Olinda. Histórias da Gravana. São Paulo: Escrituras, 2011.

BENJAMIN, Walter. O narrador: considerações sobre a obra de Nikolai Leskov. In: Obras escolhidas I - Magia e Técnica Arte Política. 7.ed. São Paulo: Brasiliense, 1994.

BONNICl, Thomas. Teoria e crítica pós-colonialistas. In: BONNICI, Thomas; ZOLIN, Lúcia Osana (Org.). Teoria literária: Abordagens históricas e tendências contemporâneas. Maringá: Eduem. 3.ed. rev. e ampl., 2009, p. 257-287.

CANDAU, Joel. Memória e identidade. São Paulo: Contexto, 2011.

FONSECA, Maria Nazareth Soares. Velho e velhice nas Literaturas Africanas de Língua Portuguesa contemporâneas. In: BARBOSA, Maria José Somerlate (Org.). Passo e compasso: nos ritmos do envelhecer. Porto Alegre: EDIPUCRS, 2003.

HALL, Stuart. A identidade cultural na pós-modernidade. Trad. Tomaz Tadeu da Silva, Guaracira Lopes Louro. 9.ed. Rio de Janeiro: DP\&A, 2004. 
. Pensando a diáspora (reflexões sobre a terra no exterior). In: Da diáspora: identidades e mediações culturais. Liv Sovik (Org.). Trad. Adelaine La Guardia Resende. Belo Horizonte: Ed. UFMG, 2013, p. 30-65.

MATA, Inocência. A essência dos caminhos que se entrecruzam. Revista Crioula, São Paulo, n. 5, p.1-19, 2009. Disponível em: <http://www.revistas.usp.br/crioula/article/viewFile/54948/58596>. Acesso em: 18 jul. 2013

. O pós-colonial nas literaturas africanas de língua portuguesa. Congresso Internacional da ALADAA (Associação Latino-Americana de estudos de Ásia e África, 10, 2000, Rio de Janeiro. Anais. Disponível em: bibliotecavirtual.clacso.org. ar/ar/libros/aladaa/mata.rtf. Acesso em: 18 ago. 2016.

- Inocência Mata: a essência dos caminhos que se entrecruzam. Revista Crioula, São Paulo, n. 5, p.1-19, 2009. Disponível em: <http://www.revistas.usp.br/crioula/article/ viewFile/54948/58596>. Acesso em: 18 jul. 2013.

QUEIROZ, Amarino Oliveira. Onde canta o ossobó: vozes literárias femininas do arquipélago de São Tomé e Príncipe. Revista da União dos Escritores de Angola, v. 6, n. 1, Luanda, ago, 2012, p. 1-11. Disponível em: <http://www.uea-angola. org/artigo.cfm?ID=882>. Acesso em: 13 jul. 2016.

RODRIGUES, Inara de Oliveira. Oralidade e questões identitárias em "Pé-de-perfume", de Olinda Beja. Revista Desenredo, v. 7, n. 1, Passo Fundo, jun, 2011, p. 19-31. Disponível em: <http:// 


\section{REVISTA CRIOULA N ${ }^{\circ} 20-2^{\circ}$ SEMESTRE/2017}

www.upf.br/seer/index.php/rd/article/view/1911/1207>. Acesso em: 08 jul. de 2015.

RUI, Manuel. Eu e o outro - o invasor ou em poucas três linhas uma maneira de pensar o texto. Comunicação apresentada no Encontro Perfil da Literatura Negra. São Paulo, Brasil, 23/05/1985. Transcrição no blog Riso - Sonhos não Envelhecem. Disponível em: <http://ricardoriso.blogspot.com. br/2007/10/eu-e-o-outro-o-invasor-ou-em-poucas-trs.html>. Acesso em: 19 maio 2015.

SANTOS, Milton. Por uma outra globalização: do pensamento único à consciência universal. 6.ed. São Paulo: Record, 2000.

Submissão: 29/08/2017

Aceite: $12 / 11 / 2017$ 